\title{
Adolescent and non-consensual anal sexual debut among Chinese men who have sex with men: a cross-sectional study
}

\author{
Weiming Tang ${ }^{1,2^{*}}$ (D), Yehua Wang ${ }^{2}$, Wenting Huang ${ }^{2}$, Dan $\mathrm{Wu}^{2}$, Fan Yang ${ }^{2}$, Yongshi $\mathrm{Xu}^{1,2}$, Jason J. Ong ${ }^{3,4}$,
} Hongyun Fu ${ }^{5}$, Bin Yang ${ }^{1,6}$, Cheng Wang ${ }^{1,6}$, Wei Ma ${ }^{7}$, Chongyi Wei ${ }^{8}$ and Joseph D. Tucker ${ }^{2,3}$

\begin{abstract}
Background: Adolescent sexual debut and non-consensual sex have been linked to higher sexual risk and STI infection in adulthood among men who have sex with men (MSM) in high-income countries. This study aimed to examine adolescent and non-consensual anal sexual debut among Chinese MSM and to evaluate factors associated with adolescent sexual debut and non-consensual anal sex.

Methods: A cross-sectional study was conducted recently among Chinese men assigned male sex at birth, $\geq 18$ years old, and who had ever engaged in anal sex with a man. Participants answered questions regarding sociodemographics, condomless sex, age at anal sexual debut with a man, and whether the first anal sex was consensual. Factors associated with an adolescent sexual debut ( $<18$ years old) and non-consensual sex at sexual debut were evaluated. We defined adolescent sexual debut as having anal sex with another man at 17 years old or younger, and the participants were asked whether their first male-to-male anal sex was non-consensual.

Results: Overall, 2031 eligible men completed the survey. The mean age of sexual debut was 20.7 (SD = 4.3) years old. 17.6\% (358/2031) of men reported adolescent sexual debut, and 5.0\% (101/2031) reported a non-consensual sexual debut. The adolescent sexual debut was associated with having more male sexual partners (adjusted OR $1.10,95 \% \mathrm{Cl} 1.06-1.15$ ) and condomless anal sex in the last three months ( $\mathrm{OOR}=1.71,95 \% \mathrm{Cl} 1.34-2.18$ ). MSM whose sexual debut was non-consensual were more likely to have condomless anal sex ( $\mathrm{AOR}=1.76,95 \% \mathrm{Cl} 1.17-$ 2.66), and to have reported an adolescent sexual debut ( $\mathrm{AOR}=2.72,95 \% \mathrm{Cl} 1.75-4.21$ ).

Conclusions: Many Chinese MSM reported adolescent sexual debut and non-consensual sex, both of which are associated with sexual risk behaviors and drive STI transmission. These findings highlight the need for designing tailored interventions for MSM who experienced adolescent sexual debut and non-consensual sex at debut.
\end{abstract}

Keywords: Behaviors, HIV, Men who have sex with men (MSM), Non-consensual sex, Prevalence, Sexual debut

\section{Background}

Adolescent sexual debut and non-consensual anal sex among men who have sex with men (MSM) may

\footnotetext{
* Correspondence: weimingtangscience@gmail.com

'Dermatology Hospital of Southern Medical University, Guangzhou 510095, China

${ }^{2}$ University of North Carolina at Chapel Hill Project-China, Guangzhou 510095, China

Full list of author information is available at the end of the article
}

contribute to adulthood high-risk behaviors and sexually transmitted infection (STI) transmission [1, 2]. Previous research with MSM suggests that adolescent sexual debut is associated with riskier sexual behaviors such as more partners, group sex, and recreational drug use [1,3]. Previous studies have also indicated people who experienced non-consensual sex, to have traumatic experiences that tend to increase their risk of HIV infection, alcohol abuse,

C C The Author(s). 2020 Open Access This article is licensed under a Creative Commons Attribution 4.0 International License, which permits use, sharing, adaptation, distribution and reproduction in any medium or format, as long as you give appropriate credit to the original author(s) and the source, provide a link to the Creative Commons licence, and indicate if changes were made. The images or other third party material in this article are included in the article's Creative Commons licence, unless indicated otherwise in a credit line to the material. If material is not included in the article's Creative Commons licence and your intended use is not permitted by statutory regulation or exceeds the permitted use, you will need to obtain permission directly from the copyright holder. To view a copy of this licence, visit http://creativecommons.org/licenses/by/4.0/. The Creative Commons Public Domain Dedication waiver (http://creativecommons.org/publicdomain/zero/1.0/) applies to the data made available in this article, unless otherwise stated in a credit line to the data. 
and poor health-seeking behaviors [2, 4-6]. However, most research on sexual debut and non-consensual sex among MSM has been focused on high-income countries $[1,7]$, and hence less is known about these phenomena in low- and middle-income countries where social taboos regarding same-sex behaviors are strongly endorsed but with limited denunciation of non-consensual sex [3]. Though non-consensual sex in MSM has been explored, $[8,9]$ limited studies to date have assessed this issue in the context of adolescent sexual debut. The intersection of these two factors is important because trauma related to early sexual experiences can lead to high-risk sexual behaviors in adulthood $[1,3]$.

Due to social and cultural pressures of the local environment, MSM in China are often subject to stigma and social discrimination $[10,11]$. As a result, they receive limited sexual health education from guardians or in schools, potentially leaving them with limited knowledge of safer sex practices $[12,13]$. Without scientifically accurate knowledge, early sexual experiences of individuals may further impact their subsequent behaviors, and facilitate engaging in risktaking behaviors, such as condomless sex and having more sexual partners. In addition, men who experienced adolescent or non-consensual sexual debut may also suffer from psychological problems that they are associated with adopting maladaptive coping behaviors (e.g., heavy drinking) linked to HIV/STI risk [2]. For example, a study of Latino MSM in the US found that those experiencing childhood sexual abuses were more likely to report depressive symptoms and heavy drinking [9]. However, the studies on adolescent sexual debut and non-consensual sex among Chinese MSM are very limited $[3,14]$, and knowing these may guide the designing of future sexual health education and interventions for Chinese MSM.

China provides a strong environment for this study. First, with the popularization of gay dating apps [15], researchers in China can easily reach MSM who were usually marginalized through online surveys, and these participants are willing to report sensitive personal information anonymously [16]. This may provide an opportunity to disclose information that they would not reveal in clinic-based surveys. Second, Chinese MSM tend to be stigmatized and discriminated, and lack sexual health education and awareness of health care [11]. Third, the social norms and attitudes toward sexuality among Chinese MSM have rapidly changed in the past decade, and Chinese MSM are more open to having sex at an earlier age $[17,18]$. In addition, Chinese MSM are disproportionally impacted by HIV, while the HIV prevalence among MSM reached $8.0 \%$ in 2015 and has remained high since then, which is about 300-400 times the prevalence observed among the general population in China $[19,20]$. In addition, extremely high HIV incidence (15.56/100 person-years) was also observed among Chinese gay men [21].
This study aimed to examine adolescent and nonconsensual sexual debut among Chinese MSM and to evaluate factors associated with adolescent sexual debut and non-consensual anal sex.

\section{Methods}

This study is a secondary analysis of baseline data from a stepped-wedge randomized controlled trial (RCT). The study evaluated the efficacy of a crowdsourced intervention in promoting HIV testing among MSM in eight Chinese cities [16], while only those who did not report HIV testing in the preceding three months in the crosssectional survey were enrolled into the RCT.

\section{Study design and sampling methods}

The nationwide, online, cross-sectional study was conducted by the University of North Carolina Project-China in July 2016. We collaborated with a gay partner seeking internet company (Blued) to recruit participants from eight cities in China (Guangzhou, Jiangmen, Shenzhen, and Zhuhai in Guangdong Province, Jinan, Jining, Qingdao and Yantai in Shandong Province, China). Blued is the largest MSM social networking mobile phone application (app) in China, with more than 40 million registers. MSM usually use this platform for socialization, seeking HIV care services, and dating. While most MSM in China uses this platform, the frequency users tend to be young, well-educated, and with high income.

For recruitment, banner advertisements linking to the online survey were sent to registered Blued users in the eight cities. Participants who clicked on the survey link were directed to the online survey hosted by Sojump (Shanghai, China, http://www.sojump.com), a widely used online survey platform in China [22]. The inclusion criteria included: being Chinese men assigned male sex at birth, at least 18 years of age, having ever had anal sex with another man (identified as MSM), and currently residing in one of the designated study cities. Eligible participants provided electronically written informed consent. An incentive of 50 RMB (\$ 7USD) was provided to the participants as a compensation for the survey completion. Quality control was assured by using the skipping patterns in the survey platform, and participants were not allowed to go back in the survey to change their previous answers, thus this study does not have the issue of missing data. We followed a checklist for reporting results of Internet e-surveys (CHERRIES) throughout the process to improve the quality and reporting of our web survey.

\section{Measures}

The anonymous online survey included measures on socio-demographics, sexual behaviors, HIV testing history, and HIV status from all participants. Socio- 
demographic information included age (as a continuous variable and further categorized into four groups: under $20,20-29,30-39$ or 40 and above), marital status (never married, currently married, and divorced or widowed), education (high school or below, some college, college/ bachelors, and masters or above), Household registration (Hukou, the hukou refers to China's national household registration system; it was categorized into the sampling city, other cities in the sampling province, or other provinces in China), and annual income ( $\leq$ \$1500 USD, \$1501-3000, $\$ 3001-5000$, \$5001-8000, or more than $\$ 8000$ ). Every participant was asked to self-report their sexual orientation (gay or bisexual), whether they disclosed their sexual orientation to non-male sexual partners (yes or no), and whether they self-identified as a transgender woman (yes or no).

Participants answered whether they had a stable male partner (yes or no), a casual male partner (yes or no), a stable female partner (yes or no), and a casual female partner (yes or no) in the last three months. We also asked the number of male partners they had in the last three months (continuous), whether they engaged in anal sex with a stable male partner in the last three months (yes or no), whether they engaged in anal sex with a casual male partner in the last three months (yes or no), whether they engaged in condomless sex with a man in the last three months (yes or no), and the type of the last partner (stable or casual partner).

Survey questions also covered HIV testing history. Participants answered questions on whether they had ever tested for HIV (yes or no) and the results from their last HIV test (positive, negative, or unknown).

With regard to male-to-male sexual debut, the participants were asked the age at which they first engaged in anal sex with a man. We defined adolescent sexual debut as having anal sex with another man at 17 years old or younger, as 18 years old was considered to be adult in China, and having sex before 18 was considered to have sex early in China [23]. In addition, the participants were asked whether their first male-to-male anal sex was non-consensual (coerced or unwilling to have sex with the partner).

\section{Statistical analysis}

Descriptive analysis was used to present the distribution of socio-demographic characteristics and HIV-related behaviors of the participants. Univariate and multivariable logistic regressions were used to evaluate factors associated with the adolescent sexual debut and nonconsensual anal sex at sexual debut, while adolescent sexual debut and non-consensual anal sex at sexual debut were treated as outcomes, to make the data analysis easier. Age, residence, educational level, and annual income were adjusted in the multivariable logistic regressions. All data analysis was completed using SAS 9.4 (SAS int. Cary, NC, USA).

\section{Results}

Socio-demographics and sex behaviors

Overall, all the 2031 MSM who finished the baseline survey were included in the current study. Their median age was $26.3(\mathrm{SD}=6.3)$ years old, while about threequarters of participants were less than 30 years old (75.8\%). In addition, the majority of the participants had household registration in the two study provinces (68.0\%), never married (85.4\%), and had attended at least some college (66.6\%) (Table 1).

About $5 \%$ of the participants (5.1\%) identified as transgender women. Close to three-quarters of the participants self-identified themselves as gay (72.5\%), and about two-thirds of the participants reported that they ever disclosed their sexual orientation to others beyond their partners (68.0\%). Overall, two-thirds of the participants reported having a regular male partner in the last three months (66.4\%), and about two-fifths of the participants reported having a casual male partner in the last three months $(40.7 \%)$.

Over $60 \%$ of the participants self-reported that they had ever tested for HIV (63.9\%). About half of the participants reported that they did not know their HIV status $(48.4 \%$, either never tested before or did not get a test result). Of those who ever tested for HIV, $5.9 \%$ reported that they were living with HIV $(62 / 1048)$.

\section{Sexual debut and non-consensual sex}

The median and mean ages of reported sexual debut were close, so we only reported mean age in the current study. Overall, 17.6\% (358/2031) of men reported adolescent sexual debut. The mean ages at anal sexual debut for participants in the age groups of $<20,20-29,30-39$ and 40 or above were 17.1 $(\mathrm{SD}=1.4), 19.8(\mathrm{SD}=2.8)$, $23.2(\mathrm{SD}=4.4)$ and $29.7(\mathrm{SD}=7.5)$ years old $(p<0.001$ for each comparison), respectively.

In addition, 5.0\% of participants self-reported that they experienced non-consensual sex at anal sexual debut (101/ 2031). The mean ages at anal sexual debut for participants who experienced and who did not experience nonconsensual sex were $15.8(\mathrm{SD}=1.5)$ and $21.8(\mathrm{SD}=4.0)$ years old $(p<0.001)$, respectively. The proportion of participants experiencing non-consensual sex at anal sexual debut with another man was higher in those whose sexual debut happened before age 18 (10.1\%), as compared to those for whom it happened at 18 or later $(3.9 \%, p<0.001)$.

\section{Factors associated with adolescent sexual debut}

Results from multivariable regression analysis revealed higher odds of adolescent sexual debut in men who disclosed sexual orientation to others (adjusted odds ratio [aOR], 1.84; 95\% confidence interval [CI], 1.40-2.43) compared to men who did not disclose their sexual orientation. In addition, men reporting adolescent sexual 
Table 1 Socio-demographic characteristics of men who have sex with men (MSM) and transgender individuals in China, 2016 ( $N=$ 2031)

\begin{tabular}{|c|c|c|}
\hline Variables & Frequency & Percent (\%) \\
\hline \multicolumn{3}{|l|}{ Age group (years) } \\
\hline$<20$ & 185 & 9.1 \\
\hline $20-29$ & 1355 & 66.7 \\
\hline $30-39$ & 397 & 19.6 \\
\hline$\geq 40$ & 94 & 4.6 \\
\hline \multicolumn{3}{|l|}{ Household registration (Hukou) } \\
\hline The sampling city & 627 & 30.9 \\
\hline Other cities in the sampling province & 754 & 37.1 \\
\hline Other provinces & 650 & 32.0 \\
\hline \multicolumn{3}{|l|}{ Marital Status } \\
\hline Never married & 1735 & 85.4 \\
\hline Currently married & 187 & 9.2 \\
\hline Divorced or widowed & 109 & 5.4 \\
\hline \multicolumn{3}{|l|}{ Education } \\
\hline High school or below & 679 & 33.4 \\
\hline Some college & 578 & 28.5 \\
\hline College/Bachelors & 695 & 34.2 \\
\hline Masters or above & 79 & 3.9 \\
\hline \multicolumn{3}{|l|}{ Annual income (USD) } \\
\hline$=<1500$ & 337 & 16.6 \\
\hline $1501-3000$ & 409 & 20.1 \\
\hline $3001-5000$ & 687 & 33.8 \\
\hline $5001-8000$ & 383 & 18.9 \\
\hline$=>8001$ & 215 & 10.6 \\
\hline \multicolumn{3}{|c|}{ Self-identified as transgender individuals } \\
\hline Yes & 104 & 5.1 \\
\hline No & 1927 & 94.9 \\
\hline \multicolumn{3}{|l|}{ Sexual orientation } \\
\hline Gay & 1473 & 72.5 \\
\hline Bisexual & 558 & 27.5 \\
\hline \multicolumn{3}{|l|}{ HIV status } \\
\hline Living with HIV & 62 & 3.1 \\
\hline At the risk of HIV & 986 & 48.5 \\
\hline Unknown & 61 & 3.0 \\
\hline Never tested & 922 & 45.4 \\
\hline \multicolumn{3}{|l|}{ Sexual orientation disclosure } \\
\hline Disclosed & 1381 & 68.0 \\
\hline Non-disclosed & 650 & 32.0 \\
\hline \multicolumn{3}{|l|}{ Age at sexual debut } \\
\hline$<18$ years old & 358 & 17.6 \\
\hline 18 years old or elder & 1673 & 82.4 \\
\hline \multicolumn{3}{|l|}{ Non-consensual sex at sexual debut ${ }^{a}$} \\
\hline No & 1930 & 95.0 \\
\hline
\end{tabular}


Table 1 Socio-demographic characteristics of men who have sex with men (MSM) and transgender individuals in China, 2016 ( $N=$ 2031) (Continued)

\begin{tabular}{lll}
\hline Variables & Frequency & Percent (\%) \\
\hline Yes & 101 \\
\hline
\end{tabular}

Note: ${ }^{\text {a }}$ We defined adolescent sexual debut as having anal sex with another man at 17 years old or younger, and the participants were asked whether their first male-to-male anal sex was non-consensual

debut with a male tended to have two or more sexual partners in the last three months $(\mathrm{aOR}=1.10,95 \% \mathrm{CI}$ : 1.06-1.15), were more likely to engage in condomless anal sex with a male partner in the last three months $(\mathrm{aOR}=1.71,95 \% \mathrm{CI}: 1.34-2.18)$, and to report that their most recent sexual partner being a casual partner $(\mathrm{aOR}=1.29,95 \%$ CI: $1.02-1.63)$ (Table 2).

\section{Factors associated with non-consensual sex at sexual debut with a male}

Results from multivariable logistic regression model demonstrated that men who reported non-consensual sex at sexual debut had higher odds of reporting adolescent sexual debut $(\mathrm{aOR}=2.72,95 \% \mathrm{CI}: 1.76-4.21)$ and engaged in condomless anal sex with a male partner in the last three months $(\mathrm{aOR}=1.76,95 \% \mathrm{CI}: 1.17-2.66)$. In addition, men whose sexual debut with a male was non-consensual were more likely to have ever tested for HIV (aOR $=1.56,95 \%$ CI: 1.01-2.42) (Table 3).

\section{Discussion}

Adolescent sexual debut and non-consensual sex at sexual debut with a male were closely correlated with subsequent condomless anal sex and among Chinese MSM. Our findings indicate that $5 \%$ of MSM in the study experienced a non-consensual sexual debut. This study adds to the current literature by providing data on sexual debut and non-consensual sex at sexual debut with a male and identifying the correlates of adolescent sexual debut and non-consensual sex among Chinese MSM, and it is a rare example of research on adolescent and non-consensual anal sexual debut among MSM in a low- and middle- income countries (LMICs) context.

We found that about $18 \%$ of the participants' experienced adolescent anal sexual debut, and at the mean age of 20.7 years old. The mean age at anal sexual debut among the participants in our study was similar to two studies in China, [3, 14] However, the mean ages of debut in this study were older than those reported among MSM in the US [5]. Similar to a study conducted in China in 2012-2013, our study also indicated that the age at sexual debut for Chinese MSM were lower among younger participants, which may partially explain the younger age of debut observed in our study. The decreasing age at anal sexual debut may reflect the sexual revolution and changing pattern for partner seeking among MSM in China. Before 2008, the main settings where Chinese MSM identified male partners were public parks, bars, or bathhouse [24]. Considering that many Chinese MSM reported discomfort with visiting gay bars or bathhouses due to fears of being identified in public as a gay man, [25] challenges identifying potential male partners may have delayed their age at sexual debut. However, the rise in popularity of the internet and social media (i.e., gay dating apps) sites for MSM in China has reduced challenges associated with sexual partner seeking, potentially facilitating sex initiation at earlier ages. In addition, as a result of rapid cultural change, social norms about sex among Chinese MSM have also rapidly changed in the past decade, which may have also made MSM more likely to initiate male-to-male anal sex early. We therefore recommend that clinicians should screen for factors like adolescent sexual debut and/or coercive sex when providing HIV services to Chinese MSM.

We found that about $5 \%$ of the participants reported a non-consensual anal sexual debut. The proportion of non-consensual anal sex in our study was lower than in a previous small study from China [14]. This proportion was much lower than observed by studies conducted in Ecuador (26.7\%) [26] and Myanmar (15\%) [27]. The limited literature on non-consensual sex among MSM also indicated that a higher proportion of MSM experienced non-consensual sex than other men and those who experienced non-consensual sex usually suffer a range of long-term health effects $[2,28]$. Previous studies have reported that MSM who experienced sexual abuse were more likely to later report depression, problematic alcohol use, more partners, more frequent condomless sex, and higher HIV prevalence $[9,29]$, and hence, on-time supportive services to help them overcome these problems are needed. Further implementation studies that aim to provide and evaluate the effect of supportive services for the victims are also needed. In addition, hotlines and online help queries should also be set up in order to provide timely supportive services to victims.

We also found that about $10 \%$ of men with adolescent anal sexual debut also reported non-consensual anal sex. Due to the limited literature on this topic, we did not find any similar study on this topic. However, the strong association between adolescent sexual debut and nonconsensual sex in our study suggests that some young gay men are being assaulted or coerced. One potential reason for this phenomenon is that there is a lack of legal protection for gay men, and in the event of a same- 
Table 2 Factors associated with adolescent sexual debut among Chinese men who have sex with men (MSM), 2016 (N=2031)

\begin{tabular}{|c|c|c|}
\hline Variables & Crude OR $(95 \% \mathrm{Cl})$ & Adjusted OR $(95 \% \mathrm{Cl})^{\mathrm{a}}$ \\
\hline \multicolumn{3}{|l|}{ Sexual Orientation } \\
\hline Bisexual & $0.88(0.58,1.14)$ & $0.97(0.74,1.27)$ \\
\hline Gay & Ref. & \\
\hline \multicolumn{3}{|l|}{ Ever disclosed sexual orientation to others } \\
\hline Yes & $190(1.45,2.49)$ & $1.84(1.40,2.43)$ \\
\hline No & Ref. & \\
\hline \multicolumn{3}{|l|}{ Transgender individuals } \\
\hline No & $0.84(0.51,1.37)$ & $0.84(0.51,1.40)$ \\
\hline Yes & Ref. & \\
\hline Number of male partners in the last three months & $1.09(1.04,1.14)$ & $1.10(1.06,1.15)$ \\
\hline \multicolumn{3}{|l|}{ Anal sex with stable male partners in 3 months } \\
\hline Yes & $1.49(1.17,1.89)$ & $1.58(1.24,2.02)$ \\
\hline No & Ref. & \\
\hline \multicolumn{3}{|l|}{ Condomless anal sex in the past 3 months } \\
\hline Yes & $1.61(1.27,2.05)$ & $1.71(1.34,2.18)$ \\
\hline No & Ref. & \\
\hline \multicolumn{3}{|l|}{ Anal sex with casual male partners in 3 months } \\
\hline Yes & $1.99(1.15,3.46)$ & $2.06(1.18,3.59)$ \\
\hline No & Ref. & \\
\hline \multicolumn{3}{|l|}{ Stable or casual partner as your last sex partner } \\
\hline Casual partner & $1.29(1.03,1.63)$ & $1.29(1.02,1.63)$ \\
\hline Stable partner & Ref. & \\
\hline \multicolumn{3}{|l|}{ Ever tested for HIV } \\
\hline Yes & $0.99(0.78,1.26)$ & $1.08(0.85,1.38)$ \\
\hline No & Ref. & \\
\hline \multicolumn{3}{|l|}{ HIV status $^{\mathrm{b}}$} \\
\hline Living with HIV & $1.36(0.73,2.52)$ & $1.30(0.69,2.46)$ \\
\hline Unknown & $0.60(0.27,1.35)$ & $0.59(0.26,1.34)$ \\
\hline At the risk of HIV & Ref. & \\
\hline
\end{tabular}

Note ${ }^{\mathrm{a}}$ Models were adjusted for participants' marital status, household registration, and education level. Due to high collinearity, age was not adjusted; ${ }^{\mathrm{b}}$ among people who ever tested for HIV

sex assault, the perpetrators were rarely held accountable, and victims remain unprotected in China. Thus, strategies such as providing community support and protective services (i.e., anonymous reporting platforms and support groups) to people who experienced nonconsensual sexual debut would be important. Legal aid and psychological counseling would also be useful, especially in China where the current criminal law does not recognize men being victims of rape [30].

We found that men who reported both adolescent and non-consensual sexual debut were more likely to engage in condomless anal sex. This finding is consistent with the limited literature on adolescent sexual debut [7, 14, 17, 31]. The script theory and life-course models indicate that the early sexual experience of a man could shape their preferences of the characteristics of certain partners, and impact their subsequent sexual behavior with different partners [14, 32]. Another potential explanation for this phenomenon is that both adolescent and non-consensual sexual debut can lead to psychological problems and self-harm, while these issues are highly correlated with condomless sex. [33, 34] However, we did not collect this information in our study, and further studies on understanding the mechanism of this phenomenon among Chinese MSM are needed. Approaches for promoting condom use during and after sexual debut among MSM would be essential.

Our study has several limitations. First, the crosssectional nature of this study means that all the correlations identified in this study should be inferred with 
Table 3 Factors associated with non-consensual sex at sexual debut among Chinese men who have sex with men (MSM), 2016 $(N=2031)$

\begin{tabular}{|c|c|c|}
\hline Variables & Crude OR $(95 \% \mathrm{CI})$ & Adjusted OR $(95 \% \mathrm{Cl})^{\mathrm{a}}$ \\
\hline \multicolumn{3}{|l|}{ Sexual orientation } \\
\hline Bisexual & $1.12(0.72,1.74)$ & $1.10(0.70,1.72)$ \\
\hline Gay & Ref. & \\
\hline \multicolumn{3}{|l|}{ Ever disclosed sexual orientation to others } \\
\hline Yes & $1.07(0.69,1.65)$ & $1.11(0.72,1.73)$ \\
\hline No & Ref. & \\
\hline \multicolumn{3}{|l|}{ Transgender individuals } \\
\hline No & $1.04(0.41,2.61)$ & $1.04(0.41,2.63)$ \\
\hline Yes & Ref. & \\
\hline \multicolumn{3}{|l|}{ Adolescent sexual debut } \\
\hline Yes & $2.77(1.81,4.23)$ & $2.72(1.76,4.21)$ \\
\hline No & Ref. & \\
\hline Number of male partners in last 3 months & $1.00(0.96,1.04)$ & $1.00(0.97,1.04)$ \\
\hline \multicolumn{3}{|l|}{ Anal sex with stable male partners in 3 months } \\
\hline Yes & $0.78(0.46,1.30)$ & $0.78(0.46,1.31)$ \\
\hline No & Ref. & \\
\hline \multicolumn{3}{|l|}{ Condomless anal sex in 3 months } \\
\hline Yes & $1.70(1.13,2.57)$ & $1.76(1.17,2.66)$ \\
\hline No & Ref. & \\
\hline \multicolumn{3}{|c|}{ Anal sex with casual male partners in 3 months } \\
\hline No & $0.77(0.37,1.59)$ & $0.80(0.39,1.67)$ \\
\hline Yes & Ref. & \\
\hline \multicolumn{3}{|c|}{ Stable or casual partner as your last sex partner } \\
\hline Stable partner & $0.70(0.47,1.04)$ & $080(0.47,1.05)$ \\
\hline Casual partner & Ref. & \\
\hline \multicolumn{3}{|l|}{ Ever tested for HIV } \\
\hline Yes & $1.43(0.92,2.22)$ & $1.56(1.01,2.42)$ \\
\hline No & Ref. & \\
\hline \multicolumn{3}{|l|}{ HIV status ${ }^{b}$} \\
\hline Living with HIV & $1.44(0.50,4.15)$ & $1.33(0.46,3.88)$ \\
\hline Unknown & $3.16(1.42,7.03)$ & $2.97(1.33,6.65)$ \\
\hline At the risk of HIV & Ref. & \\
\hline
\end{tabular}
Note ${ }^{\mathrm{a}}$ Models were adjusted for participants' marital status, household registration, and education level. Due to high collinearity, age was not adjusted; ${ }^{\mathrm{b}}$ among people who ever tested for HIV

caution. Second, we did not collect information on violence, mental health, alcohol, and substance abuse from the participants, while these variables are considered to be highly correlated with adolescent sexual debut and non-consensual sex. Third, as an online survey conducted in eight Chinese cities, our results cannot represent the general situation among Chinese MSM, as the online recruited participants tended to be young and well-educated. Fourth, as all data collected were selfreported, and since same-sex sexual activity is stigmatized in China, the rates of adolescent sexual debut and coerced sex may be underestimated in China, and social desirability bias may be present. However, we anticipate that this bias is small since the survey was online and no face-to-face meeting was involved. Regardless, our study provided useful information for a glimpse of the whole picture of adolescent sexual debut and non-consensual sex among Chinese MSM.

\section{Conclusion}

A substantial proportion of Chinese MSM reported adolescent anal sexual debut, and 5\% of MSM reported 
non-consensual anal sex at sexual debut. In addition, both adolescent sexual debut and non-consensual sex were associated with current risk behaviors such as condomless sex. These findings highlight the need for evidence-based sex education and intervention to protect the sexual autonomy of young men in the rising male-to-male sex culture in contemporary China. The findings of this study also have implications for expanding research about sexuality among youth. For example, studies evaluating the lifetime and recent nonconsensual sex events, law or legal support needs, and health service needs would be very useful for providing tailored services for MSM.

\section{Abbreviations}

Cl: Confidence interval; MSM: Who have sex with men; LMIC: Low- and middle- income countries; RCT: Randomized controlled trial; STI: Sexually transmitted infection

\section{Acknowledgments}

The authors thank all the people who contributed to this study, especially the study participants.

\section{Authors' contributions}

WT drafted this manuscript, WH, DW, BY, CW (Cheng Wang), WM, CW(Chongyi Wei) and JT collected the data, WH, YW helped the data analysis, YW, DW, FY, JO, HF, BY, YX, CW1 (Cheng Wang), KS, CW2(Chongyi Wei), WM and JT reviewed this manuscript, and WT and JT conceived this study. All the listed authors approved the final version of the manuscript for submission.

\section{Funding}

This work was supported by the National Key Research and Development Program of China (2017YFE0103800), the National Institutes of Health (NIAID 1R01Al114310-01, NIAID K24Al143471), UNC Center for AIDS Research (NIAID 5P30AI050410), NIMH (R34MH109359 and R34MH119963), National Science and Technology Major Project (2018ZX10101-001-001-003), The National Nature Science Foundation of China (81903371) and SESH (Social Entrepreneurship to Spur Health) Global. The funders had no role in study design, data collection, and analysis, decision to publish, or preparation of the manuscript.

\section{Availability of data and materials}

The datasets used and/or analyzed during the current study are available from the corresponding author on reasonable request.

\section{Ethics approval and consent to participate}

Ethical approval was obtained from the ethics review committees at the Guangdong Provincial Center for Skin Diseases and STI Control (Guangzhou, China, \#LS2016012604), and the University of North Carolina at Chapel Hill (Chapel Hill, North Carolina, \#IGHID 11413). Digital inform consent was obtained from the participants before the survey.

\section{Consent for publication}

Not applicable.

\section{Competing interests}

The authors declare that they have no competing interests. We further declare that Drs. Chongyi Wei, Weiming Tang and Joseph D. Tucker are editorial board members of the journal.

\section{Author details}

'Dermatology Hospital of Southern Medical University, Guangzhou 510095, China. ${ }^{2}$ University of North Carolina at Chapel Hill Project-China, Guangzhou 510095, China. ${ }^{3}$ Faculty of Infectious and Tropical Diseases, London School of Hygiene and Tropical Medicine, London, UK. ${ }^{4}$ Central Clinical School, Monash University, Melbourne, Australia. ${ }^{5}$ Division of Community Health and
Research, Eastern Virginia Medical School, Norfolk, Virginia, USA. ${ }^{6}$ School of Public Health, Southern Medical University, Guangzhou, China. ${ }^{7}$ School of Public Health, Shandong University, Jinan, China. ${ }^{8}$ Rutgers University, New Brunswick, NJ, USA.

Received: 24 April 2020 Accepted: 1 October 2020

Published online: 07 October 2020

\section{References}

1. Lyons A, Pitts M, Grierson J, Smith A, McNally S, Couch M. Age at first anal sex and HIV/STI vulnerability among gay men in Australia. Sex Transm Infect. 2012;88(4):252-7.

2. Ratner PA, Johnson JL, Shoveller JA, Chan K, Martindale SL, Schilder AJ, et al. Non-consensual sex experienced by men who have sex with men: prevalence and association with mental health. Patient Educ Couns. 2003; 49(1):67-74.

3. Zou H, Xu J, Hu Q, Yu Y, Fu G, Wang Z, et al. Decreasing age at first anal intercourse among men who have sex with men in China: a multicentre cross-sectional survey. J Int AIDS Soc. 2016;19(1):20792.

4. Lloyd S, Operario D. HIV risk among men who have sex with men who have experienced childhood sexual abuse: systematic review and metaanalysis. AIDS Educ Prev. 2012;24(3):228-41.

5. Glick SN, Morris M, Foxman B, Aral SO, Manhart LE, Holmes KK, et al. A comparison of sexual behavior patterns among men who have sex with men and heterosexual men and women. J Acquired Immune Deficiency Syndromes (1999). 2012;60(1):83.

6. Coxell A, King M, Mezey G, Gordon D. Lifetime prevalence, characteristics, and associated problems of non-consensual sex in men: cross sectional survey. Bmj. 1999;318(7187):846-50.

7. Nelson KM, Gamarel KE, Pantalone DW, Carey MP, Simoni JM. Sexual debut and HIV-related sexual risk-taking by birth cohort among men who have sex with men in the United States. AIDS Behav. 2016;20(10):2286-95.

8. Xu W, Zheng L, Song J, Zhang X, Zhang X, Zheng Y. Relationship between childhood sexual abuse and HIV-related risks among men who have sex with men: findings from mainland China. Arch Sex Behav. 2018;47(7):1949-57.

9. Levine EC, Martinez O, Mattera B, Wu E, Arreola S, Rutledge SE, et al. Child sexual abuse and adult mental health, sexual risk behaviors, and drinking patterns among Latino men who have sex with men. J Child Sexual Abuse. 2018;27(3):237-53.

10. Preston DB, D'augelli AR, Kassab CD, Starks MT. The relationship of stigma to the sexual risk behavior of rural men who have sex with men. AIDS Education \& Prevention. 2007;19(3):218-30.

11. Zhang J, Zheng L, Zheng Y. Moral and sexual disgust suppress sexual risk behaviors among men who have sex with men in China. Front Psychol. 2017;7:2045

12. Pijanowski S. The sexual identity development of gay men in China. Walden University: Walden University; 2018.

13. Steinhauer I. Sex and sexual education in China: traditional values and social implications: University of Colorado Boulder; 2016.

14. Pan SW, Ruan Y, Spittal PM, Pearce ME, Qian H-Z, Li D, et al. HIV vulnerabilities and coercive sex at same-sex sexual debut among men who have sex with men in Beijing, China. AIDS Care. 2014;26(6):742-9.

15. Tang W, Best J, Zhang Y, Liu F-Y, Tso LS, Huang S, et al. Gay mobile apps and the evolving virtual risk environment: a cross-sectional online survey among men who have sex with men in China. Sex Transm Infect. 2016; 92(7):508-14. https://doi.org/10.1136/sextrans-2015-052469.

16. Tang W, Wei C, Cao B, Wu D, Li KT, Lu H, et al. Crowdsourcing to expand HIV testing among men who have sex with men in China: a closed cohort stepped wedge cluster randomized controlled trial. PLoS Med. 2018;15(8): e1002645.

17. Xu R, Dai W, Zhao G, Tu D, Yang L, Wang F, et al. Adolescent sexual debut and HIV infection among men who have sex with men in Shenzhen, China. Biomed Res Int. 2016;2016:2987472. https://doi.org/10.1155/2016/2987472.

18. Zhongxin S, Farrer J, Choi K-H. Sexual identity among men who have sex with men in Shanghai. China Perspectives. 64 | march - april 2006, Online since 21 December 2006, connection on 19 April 2019. http://journals. openedition.org/chinaperspectives/598.

19. Tang S, Tang W, Meyer K, Chan P, Chen Z, Tucker JD. HIV Epidemiology and Responses among Men Who Have Sex with Men and Transgender Individuals in China: A Scoping Review. BMC Infect Dis. 2016;16(1):588. https://doi.org/10.1186/s12879-016-1904-5. 
20. Fu R, Zhao J, Wu D, Zhang X, Tucker JD, Zhang M, et al. A spatiotemporal meta-analysis of HIV/syphilis epidemic among men who have sex with men living in mainland China. BMC Infect Dis. 2018;18(1):652.

21. Huang W, Wang Y, Lu H, Wu D, Pan SW, Tucker JD, et al. High HIV Incidence Among Men Who Have Sex With Men in 8 Chinese Cities: Results From a Trial. Open forum Infect Dis. 2020;7(5):ofaa147.

22. Zhou Z, Wu JP, Zhang Q, Xu S. Transforming visitors into members in online brand communities: evidence from China. J Bus Res. 2013;66(12): 2438-43.

23. Toska E, Pantelic M, Meinck F, Keck K, Haghighat R, Cluver L. Sex in the shadow of HIV: a systematic review of prevalence, risk factors, and interventions to reduce sexual risk-taking among HIV-positive adolescents and youth in sub-Saharan Africa. PLoS One. 2017;12(6):e0178106.

24. Tang W, Yan H, Liu X, Wang N, Zhang M, Zhao X, et al. Factors associated with HIV infection among men who have sex with men in Nanjing, Suzhou and Yangzhou: a 1: 4 matched case-control study. Zhonghua liu xing bing xue za zhi= Zhonghua liuxingbingxue zazhi. 2009;30(5):448-51.

25. Tang W, Mao J, Tang S, Liu C, Mollan K, Cao B, et al. Disclosure of sexual orientation to health professionals in China: results from an online crosssectional study. J Int AIDS Soc. 2017;20(1):21416.

26. Solomon MM, Nurena CR, Tanur JM, Montoya O, Grant RM, McConnell J. Transactional sex and prevalence of STIs: a cross-sectional study of MSM and transwomen screened for an HIV prevention trial. Int J STD AIDS. 2015; 26(12):879-86

27. Linkup, Alliance, Institute B, MOR, council P. An integrated peer outreach and clinic-based intervention to improve the sexual health of young MSM in Myanmar. 2016

28. Aspin C, Reynolds P, Lehavot K, Taiapa J. An investigation of the phenomenon of non-consensual sex among Maori men who have sex with men. Culture, Health Sexuality. 2009;11(1):35-49.

29. Wu E. Childhood sexual abuse among black men who have sex with men: a cornerstone of a syndemic? PLoS One. 2018;13(11):e0206746.

30. Laws affecting HIV responses among men who have sex with men and transgender people in Asia and the Pacific: an agenda for action: UNDP, APCOM; 2010

31. Outlaw AY, Phillips G, Hightow-Weidman LB, Fields SD, Hidalgo J, HalpernFelsher $B$, et al. Age of MSM sexual debut and risk factors: results from a multisite study of racial/ethnic minority YMSM living with HIV. AIDS Patient Care STDs. 2011:25(S1):S23-S9.

32. Simon W. Sexual conduct: the social sources of human sexuality: Routledge; 2017.

33. Defechereux PA, Mehrotra M, Liu AY, McMahan VM, Glidden DV, Mayer KH, et al. Depression and Oral FTC/TDF pre-exposure prophylaxis (PrEP) among men and transgender women who have sex with men (MSM/TGW). AIDS Behav. 2016;20(7):1478-88.

34. Nowak RG, Ndembi N, Dauda W, Jibrin P, Bentzen SM, Nnaji CH, et al. Implementation of and early outcomes from anal Cancer screening at a community-engaged health care facility providing care to Nigerian men who have sex with men. J Global Oncol. 2019;5:1-11.

\section{Publisher's Note}

Springer Nature remains neutral with regard to jurisdictional claims in published maps and institutional affiliations.

Ready to submit your research? Choose BMC and benefit from:

- fast, convenient online submission

- thorough peer review by experienced researchers in your field

- rapid publication on acceptance

- support for research data, including large and complex data types

- gold Open Access which fosters wider collaboration and increased citations

- maximum visibility for your research: over $100 \mathrm{M}$ website views per year

At $\mathrm{BMC}$, research is always in progress.

Learn more biomedcentral.com/submissions 